\title{
Current Capabilities of the "VEGA-Agrometeorologist" System
}

\author{
Ivan A. Uvarov ${ }^{1}$, Mikhail A. Burtsev ${ }^{1}$, Vladimir A. Tolpin ${ }^{1}$, Olga V. Bereza ${ }^{2}$, \\ Lidiya L. Tarasova ${ }^{2}$, Anna I. Strashnaya ${ }^{2}$, Evgeny V. Vasilenko ${ }^{3}$ \\ ${ }^{1}$ Space Research Institute, Russian Academy of Sciences, Moscow, Russia \\ smis@smis.iki.rssi.ru \\ ${ }^{2}$ Hydrometeorological Research Center of Russian Federation \\ (Hydrometcenter of Russia), Moscow, Russia \\ ${ }^{3}$ State Research Center "Planeta" (SRC "Planeta") \\ Moscow, Russia
}

\begin{abstract}
"VEGA-Agrometeorologist" is the information system for comprehensive analysis of agrometeorological monitoring data. It integrates a wide range of data, primarily obtained by remote sensing methods. Various vegetation indices available in the system are particular valuable, as they make it possible to conduct a detailed study of the development of agricultural vegetation on the entire territory of agricultural lands of Russia, taking into account agro-climatic zoning. The high degree of automation of all processes ensures the continuity and homogeneity of all the data series used.
\end{abstract}

Keywords: agrometeorology, agricultural land monitoring, vegetation cover, satellite Earth observation technologies, satellite data, ground data, meteorological data, remote monitoring systems 


\title{
ТЕКУЩИЕ ВОЗМОЖНОСТИ СИСТЕМЫ ВЕГА-АГРОМЕТЕОРОЛОГ
}

\author{
И.А. Уваров ${ }^{1}$, М.А. Буриеве ${ }^{1}$, В.А. Толпин ${ }^{1}$, О.В. Береза ${ }^{2}$, Л.Л. Тарасов ${ }^{2}$, \\ А.И. Страшная 2 Е.В. Василенко ${ }^{3}$ \\ ${ }^{1}$ Институт космических исследований РАН, Москва, Россия \\ smis@smis.iki.rssi.ru \\ ${ }^{2}$ Гидрометеорологический научно-исследовательский центр Российской Федерации (ФГБУ \\ «Гидрометцентр России»), Москва, Россия \\ ${ }^{3}$ Научно-исследовательский центр космической гидрометеорологии «Планета», \\ Москва, Россия
}

\begin{abstract}
«Вега-Агрометеоролог» - информационная система комплексного анализа данных агрометеорологического мониторинга. Она интегрирует широкий спектр данных, в первую очередь, полученных дистанционными методами. Особенный интерес представляют доступные в системе различные вегетационные индексы, позволяющие подробно исследовать развитие сельскохозяйственной растительности на всей территории сельскохозяйственных земель России с учётом агроклиматического районирования. Высокая степень автоматизации всех процессов обеспечивает непрерывность и однородность рядов данных всех видов.
\end{abstract}

Ключевые слова: агрометеорология, мониторинг $\mathrm{c} / \mathrm{x}$ земель, состояние растительного покрова, спутниковые технологии наблюдения Земли, спутниковые данные, наземные данные, метеоданные, системы дистанционного мониторинга

\section{Введение}

Областью интересов агрометеорологии является изучение закономерностей формирования метеорологических и климатических условий сельскохозяйственного производства, а также разработка методов оценки влияния метеорологических и агрометеорологических факторов на развитие сельскохозяйственных культур. Также перед агрометеорологией стоит задача разработки методов оценки состояния посевов и прогнозов ожидаемого урожая.

Агрометеорология традиционно опирается на наземные данные, прежде всего, метеорологические данные, получаемые с сети гидрометеорологических станций и постов Росгидромета Также применяются наземные данные по наблюдению за состоянием и фазами развития сельскохозяйственных культур на тестовых участках. 
В Гидрометцентре России применяется специализированное программное обеспечение для обработки, анализа, хранения и визуализации агрометеорологической информации по основным сельскохозяйственным культурам. Однако оно предназначено для работы только с наземной информацией. Настоящая работа нацелена на создание инструмента комплексного анализа широкого спектра данных, в первую очередь, полученных дистанционными методами.

«Вега-Агрометеоролог» - это информационная система для комплексного анализа данных агрометеорологического мониторинга. Разработанная с использованием технологии GEOSMIS, она обеспечивает удаленный доступ пользователей к распределенным архивам данных системы и интегрированным инструментам анализа.

\section{Данные, представленные в системе}

Возможности комплексного анализа состояния сельскохозяйственной растительности обеспечиваются сочетанием разнородных данных в системе: метеорологических, спутниковых, а также различных вариантов тематической обработки.

Агрометеорологические данные собираются и обрабатываются специалистамиагрометеорологами ежедекадно. Основной поток агрометеорологических данных поступает в Гидрометцентр России по каналам связи в виде телеграмм (ежедневных и декадных) по коду КН21. Используется 29 величин, включая различные варианты оценки температуры воздуха за декаду, количества осадков, влажности и др.

Архив прогнозов погоды (реанализа) получен на основе модели NCEP Climate Forecast System Version 2 (https://rda.ucar.edu/datasets/ds094.0/). Предусмотрена работа с такими величинами, как температура воздуха, количество осадков, относительная влажность, атмосферное давление, облачность, нисходящие и восходящие потоки солнечной радиации, скорость и направление ветра. [1]

Спутниковые метеоданные поставляются НИЦ «Планета» и являются продуктом обработки измерений со спутников серии Meteosat. Представлены такие величины, как влажность почвы, продолжительность солнечного сияния, суточные осадки, минимальная температура поверхности.

Данные о природных пожарах отображают оперативную обстановку горения растительности. Они определяются с помощью специализированных алгоритмов обработки данных приборов MODIS (спутники Terra, Aqua) и VIIRS (спутники Suomi NPP, NOAA20). [2]

Тематические карты, полученные в ИКИ РАН на основе обработки спутниковых данных, включают карты растительности и карты покрытых лесом земель, подготавливаемые ежегодно с 2000 года [3], карты обрабатываемых земель, озимых и полей под паром. Также представлена глобальная карта пахотных земель IIASA, карта агроклиматических зон. Имеется ряд локальных информационных продуктов. [4]

Архивы спутниковых данных, поддерживаемые Центром коллективного пользования «ИКИ-Мониторинг» (http://ckp.geosmis.ru), получены аппаратурой различных спутников, в том числе: Terra, Aqua, Landsat, Sentinel 1, Sentinel 2, Метеор М №2 (прибор КМСС), Ресурс П (прибор ГСА), Канопус В и др. Объем архивов составляет приблизительно 2 ПБ. [5]

Базы данных статистики состояния растительного покрова регулярно обновляется на основе спутниковых данных в автоматическом режиме. [4] Возможности анализа, обеспечиваемые этим инструментом, будут рассмотрены ниже. 


\section{Возможности анализа данных}

Для работы с метеорологическими данными в системе предусмотрено несколько картографических способов изображения. В зависимости от характера данных могут использоваться изолинии, картограммы и значки. Изолинии могут быть использованы для данных любой пространственной локализации, но лучше всего подходят для данных на основе регулярной сетки, как, например, данные реанализа NCEP. При анализе данных, локализованных на метеостанциях, целесообразно применение значков. В этом случае в месте расположения метеостанции изображаются прямоугольные значки, характеризующиеся цветом и числовым значением отображаемой величины. Одновременный анализ нескольких величин возможен путем нанесения в месте расположения метеостанции сложных значков, где числовые значения, снабженные цветовой окраской, расположены в столбик. Пример такого отображения приведен на рисунке 1.

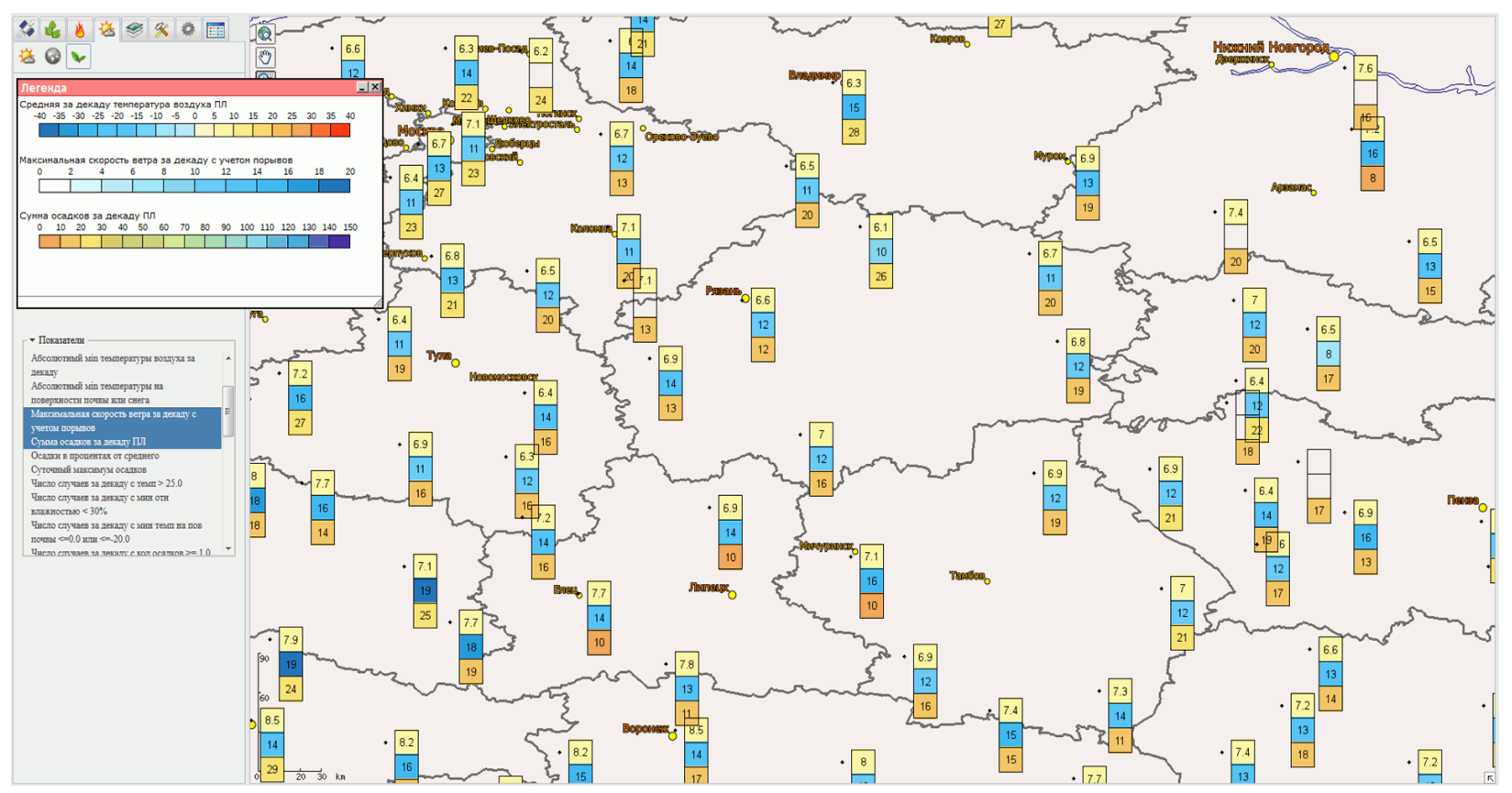

Puc. 1. Визуализация нескольких агрометеорологических величин с помощью значков

Разнообразные данные могут быть визуализированы в разрезе единиц территориального деления. Это касается, в частности, вегетационных индексов. Инструмент анализа базы данных статистики позволяет визуализировать в виде картограмм индексы NDVI, WVCI, VCNI и др. как в абсолютных величинах, так и в виде отклонения от среднего многолетнего. При этом осуществляется выборка из базы данных значений за заданный период времени и полученных на заданном типе земного покрова (отдельно анализируются средние значения вегетационных индексов на пахотных землях, землях, занятых озимыми и яровыми, лесах разного типа). Кроме того, в виде картограмм в разрезе административных районов реализована визуализация метеоданных: значений за заданный срок, средних, в виде отклонений от среднего.

Объекты наблюдения (поля) могут быть заданы пользователем для последующего анализа. Это позволит затем автоматизированно накапливать статистические данные по объекту наблюдения, строить картограммы, отображающие как количественные характеристики полей, так и возделываемые культуры.

Анализ временных рядов применим к объектам разного типа: точки, поля, районы, метеостанции. В зависимости от типа объекта, доступно построение графиков тех или иных величин. Например, применительно к метеостанциям доступен анализ временного хода агрометеоданных, в то время как для поля доступен совместный анализ временного хода 
модельных метеоданных, вегетационных индексов, с возможностью сопоставления этих данных между разными годами и разными объектами (см. рис. 2).

Работа со спутниковыми данными включает возможность визуализации как собственно исходных спутниковых изображений, так и композитных изображений, очищенных от влияния облачности, подготовленные за разные периоды времени: от 4 дней до года. При этом доступны как данные спектральной яркости в тех или иных каналах прибора, так и различные варианты синтеза, либо специальные индексы. [6]

Дополнительные возможности работы со спутниковыми данными возникают благодаря функциям цветового синтеза и яркостной коррекции изображений. Выбор информативных каналов и настройка контрастности позволяет добиться наилучшей визуальной распознаваемости объекта наблюдений. При этом возможно создание синтеза двух или трех изображений: полученных в разное время или разными системами.

Непосредственно в системе возможно проведение контролируемой или неконтролируемой классификации данных. Это позволяет в автоматическом режиме распознавать различные типы растительности и строить карты.
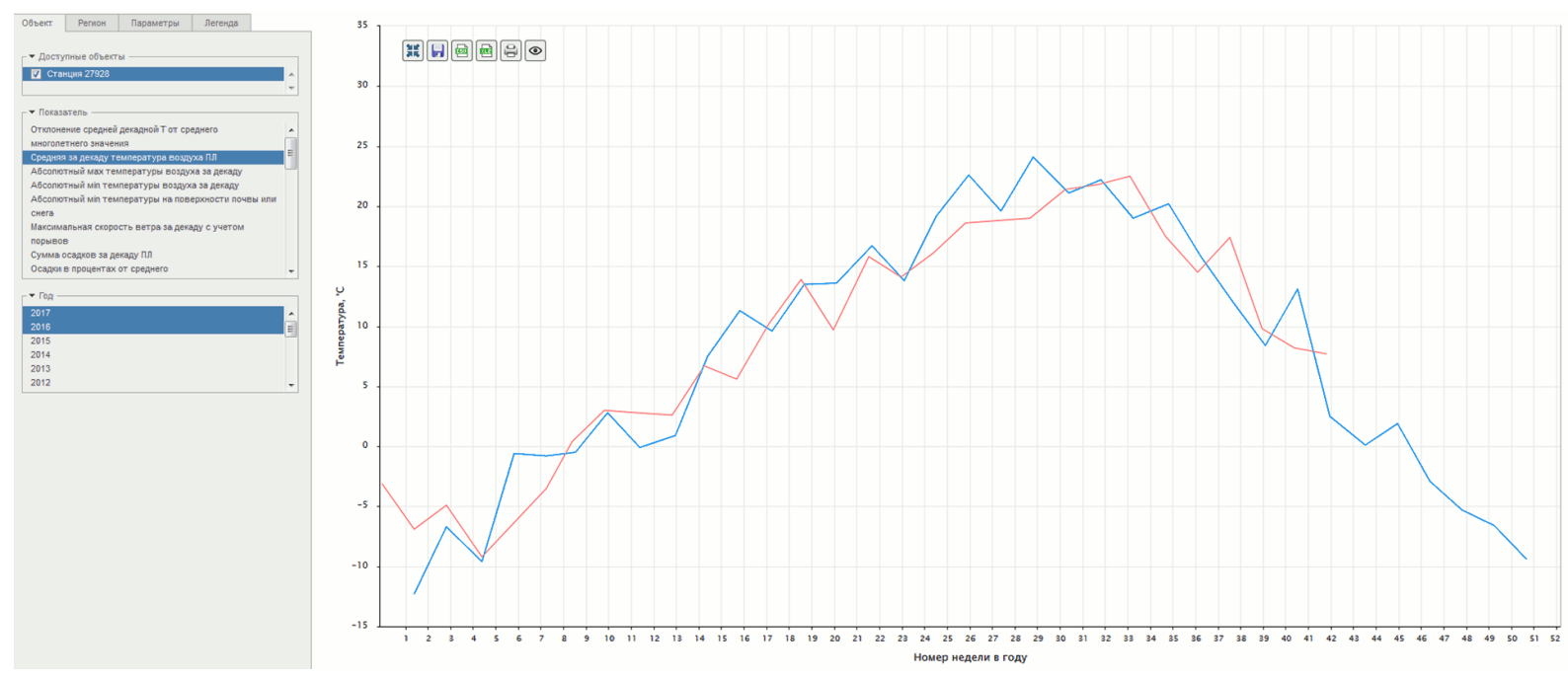

Рuc. 2. Анализ временных рядов агрометеорологических данных

\section{Заключение}

«Вега-Агрометеоролог» - первая в своем роде информационная система агрометеорологического мониторинга, интегрирующая в себе широкий спектр данных, в особенности, различных продуктов обработки данных спутниковых наблюдений. Особенный интерес представляют доступные в системе различные вегетационные индексы, позволяющие подробно исследовать развитие сельскохозяйственной растительности на всей территории сельскохозяйственных земель России с учётом агроклиматического районирования.

Высокая степень автоматизации всех процессов обеспечивает непрерывность и однородность рядов данных всех видов. Анализ рядов данных возможен как при выборе для отображения среди серии изображений и карт, так и путем построения временных профилей. Предусмотрено исследование как межсезонной, так и межгодовой динамики состояния растительности.

Система функционирует с использованием Центра коллективного пользования "ИКИМониторинг". [5]

Работа выполнена при поддержке темы «Мониторинг», госрегистрация №01.20.0.2.00164. 


\section{References}

[1] Uvarov I.A., Khalikova O.A., Balashov I.V., Bourtsev M.A., Loupian E.A., Matveev A.M., Platonov A.E., Proshin A.A., Tolpin V.A., Krasheninnikova Yu. S. Meteorological data management in framework of the satellite monitoring information systems, Sovremennye Problemy Distantsionnogo Zondirovaniya Zemli iz Kosmosa, 2013, Vol.10, № 2, pp. 30-45. (In Russian).

[2] Loupian E.A., Bartalev S.A., Balashov I.V., Egorov V.A., Ershov D.V., Kobets D.A., Senko K.S., Stytsenko F.V., Sychugov I.G. Satellite monitoring of forest fires in the 21 st century in the territory of the Russian Federation (facts and figures based on active fires detection), Sovremennye Problemy Distantsionnogo Zondirovaniya Zemli iz Kosmosa, 2017, 14(6), pp. 158-175. DOI: 10.21046/2070-7401-2017-14-6-158-175. (In Russian).

[3] Bartalev S.A., Egorov V.A., Ershov D.V., Isaev A.S., Loupian E.A., Plotnikov D.E., Uvarov I.A. Maping of Russia's Vegetation Cover Using MODIS Satellite Spectroradiometer Data, Sovremennye Problemy Distantsionnogo Zondirovaniya Zemli iz Kosmosa, 2011, 8(4), pp. 285-302. (In Russian).

[4] Loupian E.A., Savin I.Yu., Bartalev S.A., Tolpin V.A., Balashov I.V., Plotnikov D.E. Satellite Service for Vegetation Monitoring VEGA, Sovremennye Problemy Distantsionnogo Zondirovaniya Zemli iz Kosmosa, 2011, 8(1), pp. 190-198. (In Russian).

[5] Loupian E.A., Proshin A.A., Burtsev M.A., Balashov I.V., Bartalev S.A., Efremov V.Yu., Kashnitskiy A.V., Mazurov A.A., Matveev A.M., Sudneva O.A., Sychugov I.G., Tolpin V.A., Uvarov I.A. IKI center for collective use of satellite data archiving, processing and analysis systems aimed at solving the problems of environmental study and monitoring, Sovremennye Problemy Distantsionnogo Zondirovaniya Zemli iz Kosmosa, 2015, 12(5), pp. 263-284. (In Russian).

[6] Loupian E.A., Milekhin O.E., Antonov V.N., Kramareva L.S., Bourtsev M.A., Balashov I.V., Tolpin V.A., Solovyev V.I. System of operation of joint information resources based on satellite data in the Planeta Research Centers for Space Hydrometeorology, Meteorologiya $i$ Gidrologiya, 2014, 39(12), pp. 847-853. DOI: 10.3103/S1068373914120103. (In Russian). 